\title{
Research on Teaching Models of College English from the Perspective of Cognitive Poetics
}

\author{
Ling Xiao ${ }^{1, a}$ \\ ${ }^{1}$ Changsha Medical University, Changsha, 410219, China \\ ${ }^{\mathrm{a} e m a i l}$
}

Keywords: College English, Teaching models, Cognitive poetics

\begin{abstract}
With the continuous development of higher education in our country, the college English teaching model is gradually maturing. In recent years, the rise of cognitive poetics has created new opportunities for further improvement of college English teaching. This paper discusses the important role of cognitive poetics in college English teaching and the reform directions of college English teaching from the perspective of cognitive poetics to provide some references for the relative researchers.
\end{abstract}

\section{Introduction}

Cognitive poetics is a new literary theory since the 1970s. It integrates cognitive linguistics, cognitive psychology, stylistics, narratology and literary criticism, which is an outstanding achievement in interdisciplinary research. Poetics is an important field, which has a very long history, and refers to the use of cognitive poetics to study cognitive poetics research methodology, gradually mature after years of development, has become the research hotspot in recent years in the field of academic research and teaching application. Cognitive poetics is a kind of poetic interpretation method, which is based on cognitive and psychological theories. Cognitive poetics mainly studies the relationship between literature and cognition. The focus of the study is to explain the relationship between language, structure and literary effect of literary works by the process and rules of psychological cognition. For the problems existing in the real and effective solutions in the current huge employment pressure situation, affect the students interest in learning will be influenced by the pragmatism, but this is no ground for blame, as an important part of Senior English Majors in the course of literature class has unquestionable non practical function is mainly manifested as emotional education if the teachers can function properly grasp the characteristics of literature, combined with the psychological characteristics and emotional needs of students, teaching literature will rise to new heights. In addition to looking at the macro level of cognitive poetics theory overall combing and development prospects of some scholars from the micro level to specific literary texts as an example, presents the method and significance of the study of cognitive poetics. Teachers should look for the reasons from their own, and timely adjustment of innovative teaching model.

\section{Important Functions of Cognitive Poetics in College English Teaching}

Enhance Reading Level. According to cognitive linguistics, metaphor is a basic cognitive mode of human beings. It permeates everyday life, not only in language but also in thought and activity. Therefore, the concept of metaphor is also a large number of literary language, and poetry is the most prominent example. Emily is an American poet. Many of her poems are based on the theme of death, she is also known as the United States of America in the poetry of the white nun. In his most famous in the poem, the poet shows a mysterious and rich inner world to people, she with rich imagination and deep thinking on the subject of death was analyzed. And the poet uses a lot of conceptual metaphors to make a unique interpretation of death, so it is necessary to understand the metaphor in order to understand the poem. Death is the beginning of life and the journey is the two classic metaphor. By means of conceptual metaphor in cognitive poetics, the reader can feel the state of death more vividly with the help of this concept. Through the research, it can be seen that the poet 
transforms the daily and popular metaphor into a complex and novel metaphor and creates a mysterious poetic image. Therefore, many seemingly novel metaphors in literary works, in fact, are hidden behind the conceptual metaphors we have a routine, which plays an important role for students to understand the deep meaning of poetry. Retelling is divided into simple rehearsal and fine rehearsal, and the information is mainly based on fine repetition can be converted from short-term memory to long-term memory of the story is a more detailed than the daily narrative retelling. The narrative of the past can activate the existing experience or knowledge, consolidate the new knowledge. It helps to transform some knowledge into long-term memory and improve reading ability.

Cultivate Aesthetic Ability. The research and application of cognitive poetics should not only be limited to reading, but also should be based on reading, and then go beyond reading. Cognitive poetics not only pays attention to the concept of information processing, but also pays more attention to the emotional dimension of literary works. The focus of attention is not only limited to the reader's reading process, but also the author's creative process. In short, cognitive poetics will be from the perspective of individual cognition and social cognition, to study and analyze all aspects of literary creation, literary communication and aesthetic appreciation of literary works. Recently, some scholars put forward the concept of poetic similarity. This concept has aroused the resonance of many experts and professors. This concept, from the perspective of poetics and aesthetics, gives a new definition of similarity, reversing the traditional research paradigm, which only focuses on the similarity between form and conceptual meaning. This concept is helpful to make the study of cognitive poetics start with the author's creative motivation and the reader's reading experience, pay attention to the emotional effects of the discourse, and explain the origin of literary aesthetic interest. All works are the combination of language and emotion, so it is both emotional and rational. Students should put an end to the work as a writer of the rise, but should be based on the understanding of the language level to explore the potential of emotion and ethics. In the process of reading, the students are still lack of rational thinking, and lack of analysis and comparison of the ability of teachers to help students to understand the responsibility of reading is not isolated, but from the emotional sublimation to reason. Therefore, the application of cognitive poetics to English teaching can help students to improve their aesthetic ability.

Strengthen Affective Education. In order to break through the bottleneck of literature teaching, cognitive poetics and literature teaching together, which can improve the students' autonomous learning ability, and to enhance the individual emotional control ability and cognitive space, in order to fully exert the educational function of literature course. Cognitive poetics emphasizes the experience, interactivity and literary context in the process of text reading. Once the students are involved in the analysis, interpretation and interpretation of the text of the work, on the basis of the understanding of the individual to create a situation consistent with the content of the works, reading is to upgrade the act of recreation. This learning process not only strengthens the students' understanding of the work and may even create the original meaning and implied in the works of the new to accept the information passively into the interactive teaching, increase the personal experience of composition. And the scene description and language expression in the original works can leave a deep impression on the students and become the material of the students' valuable emotional experience. At the same time, through active participation in learning, the short-term memory in the classroom is extended to the long-term memory of the combination of emotion and language. Under the guidance of the theory of cognitive poetics, the teaching of literature will further strengthen the mainstream values, and put the theoretical and dogmatic empiricism into a specific example. Thus, students in appreciating the excellent language at the same time, the behavior of reading and analysis of works from the sublimation of emotion to the rational change of cognitive process, so as to correct the incorrect values, to realize the transformation of values. 


\section{Reforms of College English Teaching under the Concept of Cognitive Poetics}

Reforms of Learning Model. Students should be aware of the important role of literary works in improving their understanding of language and literacy in order to improve students' awareness of the importance of literary works. It can help the students to improve their comprehensive ability and make the students get a more comprehensive development. The teacher should guide the students' reading methods in the literature reading, and let the students think about the literature works from the perspective of cognition. After the change in the main body of the university English classroom teaching content, students take the initiative to experience and appreciate literary works has become the main content in the teaching, so the traditional teaching mode has lost value, we can through the research study to further improve the students' autonomy in college English teaching. First of all, we must change the role of teachers, teachers should become the guide in college English reading. For example, teachers can according to the syllabus or teaching contents for students to delimit a range of College English writing for students to choose, can also be in the students' research learning of students' learning outcomes are summed up, deepen the students' understanding of college English, also can be set to some problems in the students' reading process, let the students have to read. The students should take the initiative to complete the teaching tasks, independent reading related literature. In the classroom can be established on some topic as a literary work, let the students to deepen the cognition of literary works in exchange, the last link can also write an article on the literary works of the cognitive.

Reforms of Guidance Model. The application of cognitive poetics in English teaching, classroom teaching mode need to make corresponding changes to the classroom teaching as the dominant mode of cognition should be student-centered learning, discussion teaching, instead of Teacher centered teaching mode, teachers do not need to search for pictures and video racked my brain juice to make the fact of multimedia the courseware is tedious. With the widespread application of computer and multimedia technology, students' interest in these external stimuli has been getting smaller and smaller, and the desire to express their own cognitive experience is very attractive. The development history of literature in a large proportion of college English Teaching in the past, so in the classroom often have a large part of the time in the classical literature writing background and the author, and the content of the work and its influence on the development of literature and so on. This content is relatively empty, it is difficult to attract students' interest in learning, leading to the effect of college English teaching is not very good. From the perspective of cognitive poetics, we can shift the center of college English teaching to the cognitive topic. The concept of cognitive poetics is to establish the connection between the reality of life and the context of literary works. In the process of reading, the students are active in the creation of the imaginary scene, to understand the works in the real life experience, and greatly improve the students' ability to understand the meaning of literary works. Secondly, the use of cognitive science can improve students' creative ability. In the process of reading literary works, students think and map the scene, so as to help the students to construct a new artistic conception in their mind and enhance their imagination and creativity. The first thing to do is to improve the status of literary works in the teaching process, to guide students to experience and appreciate the literary works.

Reforms of Practice Model. On the basis of the students' understanding of the poetry, teachers can lose no time to carry out the theme teaching mode. The application of this model to the teaching of poetry is the Intertextuality between literary texts. In the course of teaching, we consciously choose the relevant literature to guide and enlighten the students, so that they can discuss it. As a teacher, we should adopt various training methods according to the specific conditions of adjusting the depth and form of practice, strengthen the practice of science and interest, and actively encourage students from go to Taiwan to become the protagonist, exercise classes. Teachers can use the grouping form of debate, by the two sides respectively talk about the advantages and disadvantages of popular problems, then guide the students to sort out the views of both sides and organize the available materials in view of writing and the corresponding expression in English. This not only enhanced the students' initiative and participation consciousness, changed the former by the teacher's 
spoon feeding teaching, but also developed the students to explore the spirit of cooperation, to create a positive atmosphere for learning. The traditional approach is to practice the text teaching and new knowledge to explain all after the exercise as a way to consolidate the knowledge, the students, and then by teachers through the answer form, leak filled with no knowledge point. This approach is often the root cause of the loss of attractiveness to students in the classroom. The textbook is an important basis for teaching, but we cannot echo what the books say deified. Therefore, in order to stimulate the enthusiasm of the students, teachers should be based on the actual situation of the students in the class, to exercise the form of flexible design, to adjust some exercises, so that students are easy to accept and willing to accept.

\section{Conclusion}

Cognitive poetics theory is a newly developed teaching theory in recent years, but many of the ideas contained in it are of great value to the development of college English teaching. Under the concept of the cognitive poetics, teachers can launch the innovative learning model, guidance model and practice model to cultivate students' reading level, aesthetic ability and emotional manner.

\section{Acknowledgement}

The Guidance of Categorization and Non Categorization to the Design of Graded Teaching - A Case Study of Directional and Regular Classes in Changsha Medical University. Number: Changsha Medical University Teaching, (2015) 14-22.

\section{References}

[1] Li Xuemei, Chang Junyue, The Cognitive Turn of English and American Literature Teaching under the Frame of CBI [J]. Journal of Guangdong University of Foreign Studies, 2012, 23(1):109-122.

[2] Li Jinmei, Applications of Discourse Point of Viewand Cognitive Poetics to English Poetry-Taking as an Example [J]. Journal of Hebei North University (Social Science Edition), 2012, 28(4): 33-36+47.

[3] Jiang Shuqin, Cognitive Poetics and English and American Literature Teaching [J]. Foreign Language and Literature, 2010, 26(5): 118-121.

[4] Jiang Meng, Tian Lili, Gao Mengting, Wu Deping, An ERPs study of the cognitive poetics effects of two English translations of the classical poem Feng-Qiao-Ye-Bo [J]. Foreign Language and Translation, 2016, 23(4): 1-7. 